\title{
Organisational Culture Perspective and Implementing Customer Relationship Management (CRM) in Hotel Industry: Case of a Chain Hotel in the UK
}

\author{
Roya Rahimi ${ }^{1}$
}

RECEIVED: 04/04/2014

\begin{abstract}
1 Lecturer of Tourism and Hospitality Management, Department of Marketing, Innovation, Leisure and Enterprise, Business School, University of Wolverhampton, UK; Phone: +447549664323, E-mail: roya.rahimi61@gmail.com
\end{abstract}

\section{Supervisors: Dr Ebru Gunlu}

Institution awarding the Ph. D. Degree: Dokuz Eylul University, School of Tourism and Hospitality Management (Turkey)

\section{Date of defence: 26 September 2013}

(C) 2014 International University College. All rights reserved

Citation: Rahimi, R. (2014). Organisational Culture Perspective and Implementing Customer Relationship Management (CRM) in Hotel Industry: Case of a Chain Hotel in the UK. Doctoral Dissertation Summary. European Journal of Tourism Research 8, pp. 162-165

\section{Goal and objectives of the dissertation}

Goal

Organisational culture is identified by most of researchers as one of the most important factors that enables or disables the achievement of desirable Customer Relationship Management (CRM) outcomes (Curry and Kkolou, 2004; Iriana and Buttle, 2006; Kale, 2004; Siriprasoetsin et al., 2011). Though the impact of organisational culture on CRM implementation has been the centre of attention for different researchers no study has been investigated this impact in the context of hotel industry from an empirical point of view. Hence the position taken in this research was based on the need of enhancing the knowledge of CRM implementation in the hotel industry from an organisational culture perspective. The research is designed based on the three main aims. The first aim is empirically investigating the impact of organisational culture on CRM implementation. Considering the importance of organisational culture in CRM implementations, the research's second aim moved toward investigating the approach and strategies that could help hotel businesses to improve their organisational culture and consequently their CRM outcomes. As the third and final aim, the research investigated the potential overlap between guests' satisfaction criteria and intended satisfaction criteria by implementing CRM.

\section{Objectives}

1. To review the literature and identify the organisational culture factors with potential impact on CRM outcomes. 
2. To review the literature and identify an organisational culture model with the ability to measure these factors.

3. To empirically investigate the impact of identified factors on CRM implementation.

4. To rank the organisational cultural factors based on their importance for CRM outcomes.

5. To find the best approach and strategies to improve the affective organisational culture factor.

6. Based on the finding, to suggest managerial implications for overcoming cultural barriers in order to leverage the full potential of CRM projects.

7. To find the potential overlaps between intended CRM outcomes and customer satisfaction criteria.

8. Based on the finding, to suggest managerial implications about specific guest satisfaction criteria in budget hotels to excel in them towards outperforming competitors and retaining the interest of existing and potential customers.

\section{Methodology}

The research is conducted base on case study approach and a chain hotel from the UK was selected as the case of the research. The study is designed based on mixed methods via sequential triangulation technique (Creswell et al., 2003; Johnson, 2007). Accordingly, the research is designed base on three sequential phases; starting with phase one (first aim) with quantitative approach to empirically investigate the impact of organisational culture on the CRM implementation. Research's instrument for this phase is a questionnaire adapted from two standard questionnaires of Denison Organisational Culture Survey (DOCS) (Denison and Neale, 1996) and Mendoza CRM Model (Mendoza et al., 2006). The total population considered as managers of all branches and initially 346 questionnaires were distributed and 214 (58\%) completed questionnaires were used for the statistical analysis. Collected data were subjected to correlation and multiple regression tests by using Statistical Package for the Social Sciences (SPSS) version 21.

This is then followed by the second phase (second aim) through qualitative approach to find how important organisational culture factors from phase one can be improved. In this phase 12 interviews were conducted with mangers of four branches. Mangers were asked about approaches and strategies that could improve organisational culture. Deductive theory via template analyses (King et al., 2004) was used for analysing the interviews' transcripts.

Phase three (third aim), with qualitative approach is investigated on the potential overlap between intended CRM outcomes of the case study and real guests' satisfaction criteria. Both interviews (inductive approach) and content analysis of guests' comments (Neuendorf, 2002) were used toward achieving the goal of this phase.

\section{Results}

The empirical results of the first phase demonstrate that in the context of hotel industry, there is a positive and meaningful relationship between organisational culture factors of consistency, adaptability, staff involvement and sharing the mission and vision of the organisation and CRM implementations, The result of the multiple regression analysis shown that though the organisational culture factors are positively correlated with CRM implementation, CRM implementation is not dependent on all of them. The results of the second phase of the research suggested a list of strategies that can help to improve organisational culture and consequently, CRM outcomes. These strategies will be explained in practical application of the dissertation. The results of the third phase of the research shown there are gaps between intended outcomes of CRM programme and guests' satisfaction criteria. Comments related to CRM were comprised of only $28 \%$ of satisfaction comments and $72 \%$ of satisfaction comments were belonging to the hotels' core products.

\section{Theoretical Conclusions}

According to the empirical results of the first phase there is a positive and meaningful relationship between organisational culture and CRM outcomes, which is the answer to the gap of the literature (Iriana and Buttle, 2006) and in line with pervious qualitative studies (Chen and Popovich, 2003; Raman et al., 2006; Verhoef 
Organisational Culture Perspective and Implementing Customer Relationship Management (CRM) in Hotel Industry: Case of a Chain Hotel in the UK. Doctoral Dissertation Summary.

and Langerak, 2002). The empirical results further showed that while all of these factors are important some of them have a higher level of impact on CRM implementations. Among these four factors, sharing the mission and vision of the CRM programme among the staffs has the most impact on CRM outcomes. This impact then followed by adaptability and consistency of the organisation and staff involvement. The results of the third phase of the research suggest in the budget hotel context, guests are not looking for customised and personalised products and services, which is one the main aims of CRM, instead they are more interested in a short and comfortable stay and they attach more importance to value for money.

\section{Practical Application of the Dissertation}

In addition to theoretical contribution, this dissertation will benefit hotel managers to improve their organisational culture and eventually their CRM outcomes. Organisational culture readiness is one the most important essentials in CRM implementation initiatives. Any hotel business that wants to undertake a CRM project should spend time learning about its organisational culture and assess its strengths and weaknesses. Organisational culture should be compared and improved based on the required cultural characteristics of a successful CRM application. Considering the importance of sharing the organisation's mission and vision among the staff it can be recommend that mission and vision statements of the hotel should be clearly defined and the mission and vision of CRM programme should be in line with them. Defined mission and visions should be shared with staff both verbally and written, on regular and consist bases. The second important organisational culture factor for successful CRM outcomes is adaptability of the organisation. Toward having and adaptable organisation, quick and efficient respond to the needs of the guests should be the main job description of all staff. Consistency is the third important factor for having successful CRM outcomes. Toward achieving consistency, organisations should keep their staff updated about the business trends via regular meetings. There should be daily meetings in the organisation and explaining about what is happening or going to be happening and what the organisation's expectations from the staff are. Having training programs to keep staffs' skills and abilities up to the required standard is important for the consistency of the organisation. Empowering the staff to solve the problem and training them to deal with problems in the same way also will result in improvement in consistency in problem resolutions and consequently services. Staff involvement was found as the last important factor for achieving CRM and organisation's goals. Toward having more involved staff, a supportive management style via standing next to the team and supporting them in the difficult situations is required. Staff's satisfaction should be one of the organisation's main attentions. The organisation should keep an open and honest communications with staffs and encourage them to talk about their concerns and problems. Having staff satisfaction surveys or monthly meetings for solving the problems and providing the staff with pleasant working environment should also be in the attention of the organisation.

In hotels customers use specific criteria to distinguish amongst those hotel companies that meet their threshold product or service requirements. Hotel company not only should identify the specific criteria of its target customers but that company should also aim to excel in these if it is to outperform its competitors and retain the interest of its existing and potential customers.

\section{Content of the Dissertation}

Abstract of chapter one: Introduction

This chapter presents the research background and contextualises the study and specified the main purpose and specific objectives of the study.

\section{Abstract of chapter two: Literature Review}

This chapter discusses the previous literature on organisational culture, CRM and the impact of organisational culture on CRM implementations. Different models of organisational culture and CRM also discussed. The constructs forming the theoretical framework were reviewed, with particular emphasis on the causal relationships between variables. 
Abstract of chapter three: Research Method This chapter includes three parts and explains the research approach and strategies used for each aim of the research.

\section{Abstract of chapter four: Data Analysis}

This chapter includes three parts addressing the results related to the three aims of the research. The first part starts with a descriptive analysis of the respondents followed by the results of the correlation and multiple regression tests. The second part explains the result of the interviews and in the third part explains the overlaps between interview outcomes and the guests' comments.

\section{Abstract of chapter five: Discussion}

It firstly provides an overview of the research study, followed by a recapitulation of major findings. Study objectives, thereafter examined, ensured they were achieved. The final section identifies limitations of the present study and makes recommendations for future research.

\section{References}

Chen, I., and Popovich, K. (2003). Understanding Customer Relationship Management (CRM): People, Process and Technology. Business Process Management Journal, 9(5), 672-688.

Creswell, J., Plano Clark, V., and Gutmann, M. (2003). Advanced mixed methods research. In Tashakkori, A. and Teddlie, C. (Eds) Sage Handbook of mixed methods in social and behavioural research; 209-240, United States: Sage Publications.

Curry, A., and Kkolou, E. (2004). Evaluating CRM To Contribute To TQM improvement - A Cross Case Comparison. The TQM Magazine 16(5), 314-324.

Denison, D.R, and Neale, W. (1996). Denison Organisational Culture Survey. Aviat: Ann Arbor, MI.

Iriana, R., and Buttle, F. (2006). Customer Relationship Management (CRM): system implementations. International
Journal of Knowledge, Culture and Change Management 6(2), 1-15.

Johnson, R. Burke, Anthony J. Onwuegbuzie, and Lisa A. Turner. (2007). Toward a definition of mixed methods research. Journal of mixed methods research, 1(2), 12-133.

Jöreskog, Karl G., and Dag Sörbom (1996). LISREL 8: User's reference guide. Scientific Software International.

Kale, S. (2004) CRM failure and the seven deadly sins. Marketing Management Journal, 13(5), 42-46.

King, N., Cassell, C., and Symon, G. (2004). Using templates in the thematic analysis of texts. In C. Cassell,, and G. Symon (2004) Essential guide to qualitative methods in organisational research. London: Sage, 256-270.

Mendoza, L., Marius, A., Pérez, M., and Grimán. (2006). Critical Success Factors for a Customer Relationship Management strategy. Information and Software Technology, 49(8), 913-945.

Neuendorf, K. A. (2002). The content analysis guidebook. London: Sage.

Raman, P., Wittmann, C., and Rauseo,, N. (2006). Leveraging CRM for sales: the role of organisational capabilities in successful CRM implementation. Journal of Personal Selling and Sales Management, 26(1), 39-53.

Siriprasoetsin, P., Tuamsuk, K., and Vongprasert, C. (2011). Factors affecting customer relationship management practices in Thai academic libraries. The International Information and Library Review, 43(4), 221-229.

Verhoef, P. C. and Langerak, J. (2003). Understanding the effect of customer relationship management efforts on customer retention and customer share development. Journal of Marketing, 67, 30-45. 